\title{
PARA UMA CRÍTICA MACINTYREANA DA FILOSOFIA ANALÍTICA
}

\author{
Towards a Macintyrean critique of Analytic philosophy
}

Alberto Leopoldo Batista Neto

UFRN

Resumo: A filosofia analítica constitui uma das mais importantes tradições filosóficas do século XX. Porém, a ausência de acordos sobre princípios e teses em comum acaba prejudicando a compreensão de sua identidade e a alegação, comum entre seus representantes, de constituir uma forma superior de racionalidade. $O$ projeto filosófico de Alasdair Maclntyre permite aprofundar essa crítica.

Palavras-chave: Filosofia Analítica, Metafilosofia, Racionalidade, Alasdair Maclntyre, Virada Linguística, Lógica, Liberalismo.

Abstract: Analytic philosophy is one of the most important philosophical traditions of $20^{\text {th }}$ century. But the absence of agreement concerning shared principles and thesis leads to misunderstanding its identity and to argue - like many of its representatives do - that is a superior form of rationality. Alasdair MacIntyre's philosophical project provides resources to deep such critique.

Keywords: Analytic Philosophy, Metaphilosophy, Rationality, Alasdair Maclntyre, Linguistic Turn, Logic, Liberalism

\section{Introdução}

O projeto de crítica à sociedade moderna desenvolvido por Alasdair Maclntyre ao longo de toda a sua trajetória acadêmica assume, a partir da publicação de sua obra After Virtue (2007), uma dimensão programática, norteada por uma perspectiva progressivamente mais informada pelo aristotelismo e pelo tomismo, mas desenvolvida em uma elaborada teoria metafilosófica (nitidamente inspirada em discussões da filosofia da ciência, e em particular nas teses de Thomas Kuhn e Imre 
Lakatos) que lhe permite passar juízo sobre concepções de racionalidade tomadas em sentido amplo.

Em suas principais obras, e em especial na trilogia inaugurada pelo já mencionado livro e que se complementa (e corrige) nos títulos Whose Justice? Which Rationality? (1988) e Three Rival Versions of Moral Enquiry (1990a), tal programa se desdobra notavelmente tomando como objeto a racionalidade moral, sendo Maclntyre conhecido principalmente por sua defesa de uma ética das virtudes de corte aristotélico-tomista a partir do panorama descortinado por seu peculiar programa de pesquisa. É certo, porém, que o programa macintyreano é dotado, por si mesmo, de muito maior escopo, sendo mesmo uma posição característica daquele filósofo que os diversos setores da racionalidade filosófica são em grande medida interdependentes. De fato, Maclntyre dá, mesmo nessas obras, diversos apontamentos de como sua perspectiva repercute sobre o tema da racionalidade teórica, e em algumas publicações, como nos ensaios publicados na coletânea The Tasks of Philosophy (2006), mostra de modo mais explícito como afeta a discussão de problemas clássicos da filosofia teórica, como o da admissão de "primeiros princípios" e o das teorias sobre a verdade.

Sendo um filósofo estabelecido no ambiente universitário anglófono, Maclntyre está em constante diálogo com filósofos analíticos, e seu nome é frequentemente vinculado a seu movimento filosófico. Em certos aspectos, a obra de Macintyre se encontra em continuidade com a de filósofos associados ao chamado "tomismo analítico", tais como Elizabeth Anscombe, Peter Geach e Philippa Foot (v. MICHELETTI, 2009). No entanto, não somente estende sua conversa filosófica a representantes de outras tradições (tais como a filosofia antiga e medieval, a filosofia escocesa moderna, o marxismo, a psicanálise, o pós-estruturalismo) como, em certo sentido, provê apontes importantes para a elaboração de uma crítica compreensiva à tradição analítica em filosofia enquanto tal. Pode-se mesmo dizer que o pensamento de Maclntyre - em sua insistência sobre a unidade do empreendimento investigativo, 
em sua compreensão das tradições de pesquisa, em sua apreciação negativa da tradição liberal, em sua crítica aos modos institucionalizados de produção filosófica ataca frontalmente os pressupostos básicos que deram à filosofia analítica o seu perfil.

A tradição analítica - à primeira vista, pelo menos - parece especialmente recalcitrante a uma avaliação compreensiva, em bloco. Não apenas se observa uma tremenda heterogeneidade em teses e abordagem como parecem mesmo contrários à metodologia característica dos filósofos que se inscrevem sob a rubrica de analíticos os aportes mais compreensivos e transdisciplinares. Isto, juntamente com uma renhida resistência à penetração de considerações históricas no campo da filosofia, acabou tendo por resultado que os autores com suficiente competência para dominar o tipo de ferramental técnico e conceitual de ordinário empregado pelos filósofos analíticos só raramente se interessassem por construir histórias ou apresentações panorâmicas daquela tradição. No entanto, precisamente esses traços que tornam a tradição analítica, enquanto tradição (sendo um estilo de filosofia que procura emancipar-se da espécie de vínculos históricos que são constitutivos de uma tradição), pouco transparente a seus participantes, constituem um elemento importante para uma crítica inspirada em Maclntyre - e aqui é particularmente relevante o que Maclntyre tem a dizer acerca da constituição da tradição liberal no pensamento moral e político.

\section{Crise de identidade da Filosofia Analítica}

O que hoje se conhece como "filosofia analítica" é um fenômeno bastante heterogêneo e multifacetado, que se alastra por uma diversidade de áreas temáticas que parecem incluir a totalidade do campo de investigação tradicional da filosofia: metafísica, ética, epistemologia, filosofia política, teologia natural, estética etc., dando ainda, pela peculiar ênfase investida, lugar ao surgimento de disciplinas que, ainda que se movam amiúde na órbita daquelas outras (ou em seus pontos de interseção), mereceram uma constituição como especialidades particulares: filosofia da linguagem, lógica filosófica, filosofia da ciência, filosofia da lógica, filosofia da matemática, filosofia 
da mente (v. GLOCK, 2008). Em seu estabelecimento, haure de ramos da filosofia continental do século XIX em seu diálogo crítico com Kant acerca das condições do conhecimento (e em especial no que diz respeito ao conhecimento matemático) e da tradição do empirismo britânico (que tem raízes mais remotas na "virada nominalista" do pensamento escolástico no século XIV, mas toma sua forma mais imediatamente reconhecível a partir do século XVII), e é propriamente na Grã-Bretanha das primeiras décadas do século $X X$ que assume consistência como movimento. Originalmente, há uma forte preocupação em oferecer oposição ao idealismo (frequentemente visto como alienígena ao temperamento filosófico anglo-saxão) e restaurar um "senso comum" filosófico que seja ainda compatível com uma visão essencialmente aberta às contribuições da ciência natural. O ferramental da nova lógica, sobretudo em sua versão mais completa desenvolvida por Frege, servia ainda (a partir, principalmente, de Russell) como instrumento para uma análise conceitual (aqui ainda compatível com um programa realista em metafísica) destinada a desfazer as perplexidades da "filosofia tradicional" por meio de paráfrases que revelassem a forma lógica genuína dos enunciados, frequentemente descontínua com a sua forma gramatical de superfície. A conversão desse programa em um que dá centralidade à noção de análise linguística como modo de dissolver os problemas tradicionais da filosofia - noção que exerceria enorme influência sobre a configuração posterior do movimento, viria com Wittgenstein (v. GLOCK, op. cit.; AKEHURST, 2010; HACKER, 2007).

O que se chamou "a virada linguística", expressão que ganhou terreno após a publicação de influente coletânea de artigos organizada por Richard Rorty (1992, publicada inicialmente em 1967), que a atribui a Gustav Bergmann, não tardou a identificar-se como o próprio fulcro do movimento analítico desde então. As obras anteriores do "cânon", como as de Frege, Russell e Moore (e, em certo sentido, também Bolzano), a ele foram admitidas, pode-se dizer, por entreverem potencialidades que apenas então foram plenamente amadurecidas. Um título tomado comumente como sinônimo de "filósofo analítico" passou a ser o de "filósofo 
linguístico". O ensaio introdutório de Rorty à coletânea tornou-se ainda célebre por consagrar a distinção entre duas linhas principais da "filosofia linguística": a dita filosofia da linguagem ideal e a dita filosofia da linguagem ordinária (as quais procura ainda aproximar, na medida em que a determinação do "sentido ordinário" das expressões envolve uma medida de reconstrução). Elencando uma série de dificuldades e objeções enfrentadas por filósofos linguísticos e mostrando a extensão em que crê poderem ser respondidas (e as mais promissoras perspectivas para o seu desenvolvimento no futuro), Rorty, no entanto, admite que a revolução filosófica da virada linguística apresenta um genuíno desafio à filosofia, suficiente para por em guarda toda a tradição filosófica e erguer o período subsequente ao estatuto de uma das mais grandiosas eras da história da disciplina.

Em pós-escritos para edições posteriores, vê-se mais cauto. Com efeito, a partir da década de 1960, o paradigma linguístico vai gradualmente perdendo seu monopólio no campo da filosofia analítica. No interior dos debates que esse paradigma ocasionava, especialmente com Grice e Searle, houve mesmo um afastamento de algumas premissas metodológicas próprias à virada linguística, abrindo espaço para a projeção da chamada "filosofia da mente", que chegou mesmo a dominar o panorama de produção e publicação no ambiente filosófico "analítico" e representa, em certo sentido, um retorno a Descartes e sua progênie filosófica imediata (embora a constante menção a "atitudes proposicionais" e a forma dos debates, por exemplo, entre defensores do conexionismo e proponentes da tese da "linguagem do pensamento", mostrem que as considerações lógico-linguísticas ainda ocupam aqui um posto destacado). O trabalho filosófico de Quine, diluindo as fronteiras entre a filosofia e as ciências, atacando os princípios que ora recomendavam o método da "análise linguística" (tais como a distinção entre enunciados analíticos e sintéticos e o isolamento do conteúdo cognitivo das sentenças) e abrindo espaço para as discussões sobre ontologia, também ajudou a alterar substancialmente a face do movimento (mais uma vez, sem realmente marginalizar os aspectos lógico-linguísticos - como se 
vê pela importância do conceito de "ascensão semântica", por exemplo) [v. GLOCK, op. cit.]. Em 1975, Ian Hacking publica a obra Why Does Language Matter to Philosophy?, em que questiona todo o projeto da virada linguística: assim como a "virada epistemológica" de Descartes interpôs entre o sujeito cognoscente e a realidade conhecida as representações mentais privadas, a virada linguística interpõe os significados incorporados ao discurso público - e as mesmas dificuldades céticas sobre "mediação" e "acesso" ao mundo se veem replicadas. Rorty rejeita algumas conclusões específicas de Hacking, mas se vê progressivamente inclinado a propor a insustentabilidade da "tese linguística" (que tenta reduzir os problemas filosóficos a problemas de linguagem) e se aproxima de uma posição davidsoniana, que radicaliza o naturalismo proposto por Quine, atacando como "último dogma do empirismo" o dualismo entre esquema e conteúdo (v. GLOCK, 2003).

Uma abordagem linguística mais explícita permanece no horizonte, por exemplo, com o influente projeto de Michael Dummett (v. 1991), que não propõe propriamente uma dissolução linguística dos problemas da filosofia (que identifica a sua etapa destrutiva), mas afirma que sua resolução própria depende de uma opção prévia por uma teoria semântica adequada (que deve capturar as condições de uso, e possivelmente filtrá-las por razões de assertibilidade: a propósito, a combinação entre uso ordinário e reconstrução e a interação entre métodos formais e análise "informal" de significados em Dummett aponta para um compromisso entre as abordagens da linguagem ideal e da linguagem ordinária). Com efeito, Dummett repropõe a ideia da virada linguística como uma característica central da filosofia analítica, cuja gênese procura reportar em sua obra The Origins of Analytical Philosophy (1993). Esta obra integra um gênero crescente de estudos históricos sobre a filosofia analítica, que alguns filósofos identificam como forma de reação à crise identitária que mais e mais se reconhece. Segundo Aaron Preston (2010), a busca pelas condições de origem da filosofia analítica é tomada como um meio para permitir, de um ponto de vista mais propriamente filosófico, identificar os traços definidores daquele modo de filosofar. A 
posição de Dummett, porém, embora se alinhe com aquilo que Preston denomina a Concepção Tradicional de Filosofia Analítica, é idiossincrática entre aquelas que caracterizam a produção contemporânea. Partindo dos textos de Rorty que integram as diversas edições da coletânea a que nos referimos, Timothy Williamson (2004), um dos nomes de destaque da nova geração de filósofos analíticos, considera superado o fenômeno da virada linguística, subsumido, para ele, no que intitula uma "virada representacional" (o que parece ir na contramão da tendência de Quine, Davidson, Hacking e Rorty a que aludimos acima), que também abriria espaço para a reabilitação da metafísica (ao menos tematicamente próxima à metafísica tradicional) em chave modalista, como se vem praticando com crescente interesse desde Kripke.

Esses dois exemplos de tomada de posição, procurando, respectivamente, restringir a concepção de filosofia analítica a uma versão mais "linguística" e abrindo-a para outras formas (específicas) de prática filosófica, é ilustrativa do tipo de divergência que hoje se torna comum entre os que procuram olhar para a tradição analítica desde uma perspectiva metafilosófica. Comentando sobre o texto de Williamson, Peter Hacker (2007) se revela apreensivo quanto à ideia de abandonar a perspectiva linguística e dar espaço à "pseudociência" da metafísica, em estilo "analítico clássico". Interessa observar que, em outro artigo (1998), Hacker defende que a unidade da filosofia analítica é principalmente histórica, sendo aquele título um termo que não enseja consenso sobre significado, de modo que se teria a liberdade, e mesmo o dever, de impor-Ihe um. Que, portanto, filósofos analíticos procurem aplicar o rótulo do movimento a que se afiliam àquelas produções que Ihes pareçam mais próximas à sua própria concepção de como deve ser praticada a filosofia, parece uma atitude legitimada, em alguma medida ao menos, pela atual situação na filosofia analítica. O próprio Rorty, em uma nota a seu pós-escrito Twenty-Five Years After à já referida coletânea, reconhece que a maioria dos filósofos analíticos em 1990 já não se veem mais como "filósofos linguísticos", e que os seus problemas característicos de tal maneira variam com o tempo, numa história a que os seus participantes tipicamente 
dão muito pouca atenção (assim como aos condicionantes culturais que essa história carrega), e aquele movimento se vê muito mais propriamente delimitado pelos professores que discutem aqueles problemas em determinadas partes do mundo.

É claro que esse tipo de delimitação sociológica requer uma determinação ulterior. O que caracterizaria um tal grupo de professores como praticantes de "filosofia analítica"? Já se fala do surgimento de uma filosofia "pós-analítica". Em todo caso, institucionalmente, a filosofia analítica não se encontra em estágio degenerativo (v. PRESTON, op. cit.). Antes, pelo contrário, mantém-se um movimento firmemente estabelecido e em expansão para áreas do globo distantes, geográfica e culturalmente, do ambiente anglófono em que firmou sua inicial residência (inclusive no Brasil ${ }^{1}$ ). Há a clara consciência de uma herança comum, de um estilo próprio, de um tipo de abordagem facilmente identificável pela avaliação das suas principais publicações. Há mesmo a tendência a identificar a filosofia analítica à "boa filosofia" (v. PRESTON, op. cit.). É claro que, na própria constituição da filosofia analítica, há essa premissa axiológica. A revolução filosófica proposta pelos analíticos tinha justamente entre seus propósitos o mostrar a caducidade e esterilidade dos modos tradicionais de fazer filosofia. A identidade da filosofia analítica enquanto movimento está historicamente relacionada ao contraste que estabelecia com a chamada "filosofia continental", sempre associada à arbitrariedade, à obscuridade e ao parco cuidado argumentativo (v. AKEHURST, op. cit.; CRITCHLEY, 2001). Entretanto, com a falha da "tese linguística" em se estabelecer como premissa metodológica comum, com a abertura à especulação metafísica, com a própria progressiva aproximação de diversos filósofos analíticos a autores continentais paradigmáticos, a alegação de superioridade passa a partilhar das dificuldades do problema da identidade.

Ainda assim, a identificação entre "filosofia analítica" e "boa filosofia" permanece uma prática comum entre os profissionais da filosofia no mundo

\footnotetext{
${ }^{1}$ Representantes da filosofia analítica estão em solo brasileiro desde a década de 1930, mas a sua presença nos anos recentes é bem mais notável, reunindo-se a Sociedade Brasileira de Filosofia Analítica em congressos bienalmente desde 1991. Veja-se em sbpha.org.br.
} 
anglófono. Preston reporta diversos casos em que o corporativismo dos partidários da filosofia analítica se mostra como elemento central na organização acadêmica do estudo da Filosofia naquele quadrante. A própria tendência recente ao pluralismo, com a abertura a aspectos do pensamento de fenomenólogos e hermeneutas, seria exógena àquela tradição, resultando da chamada "revolta pluralista" do fim da década de 1970, quando filósofos associados a correntes de pensamento marginais (naquele contexto) protestaram contra a hegemonia da filosofia analítica e a política de exclusão a esta associada. Nesse sentido, parece haver alguma motivação para a atitude de filósofos analíticos (como Dummett e Hacker) de restringir a aplicação da expressão "filosofia analítica" à prática filosófica que se mantém no interior dos marcos metodológicos que deram caráter à virada linguística, reservando àqueles que emergem do movimento e permanecem em diálogo com ele o rótulo de "pósanalíticos". Entretanto, isso ainda pode ser enganador. Como vimos, autores inequivocamente vinculados à tradição analítica, como Moore e Russell, somente $a$ posteriori podem ser associados à virada linguística. Ademais, há suficiente divergência sobre o significado e as implicações desse fenômeno (vejam-se, por exemplo, os artigos incluídos na coletânea organizada por Rorty) para reconhecer a presença de um grau não desprezível de pluralismo metodológico entre os filósofos analíticos.

Poder-se-ia, talvez, procurar definir a filosofia analítica como uma modalidade de filosofia preocupada com o rigor de argumentação e a clareza expositiva que dá ainda especial atenção à análise de termos e conceitos. Em semelhante tentativa há, claro, algo da auto-indulgência característica da identificação da filosofia analítica com a (boa) filosofia simpliciter. Seja como for, essa caracterização tende a transcender as fronteiras históricas normalmente atribuídas à filosofia analítica e atingir autores e correntes bastante distantes entre si no tempo e no espaço. Tal é a atitude expressa de Dagfinn Follesdal (1997), para quem a filosofia analítica não pode ser definida por teses e problemas comuns nem por um método compartilhado, mas pela centralidade conferida a argumentos e à justificação das posições. Com isso, porém, admite a 
entrada de membros improváveis como Aristóteles, Sto. Tomás de Aquino e Descartes; e a considera menos claramente franqueável a um pensador central à tradição analítica como Wittgenstein (ao menos o Wittgenstein pós-Tractatus).

Há ainda um ponto em que a filosofia tal como praticada na tradição analítica diverge radicalmente daquela praticada por Aristóteles, Sto. Tomás ou Descartes (v. PRESTON, op. cit.): enquanto estes autores estão preocupados em integrar as discussões de problemas isolados numa visão compreensiva, e relacionar a prática filosófica a uma compreensão global da vida humana e de seus fins próprios, os filósofos analíticos tendem a se concentrar na discussão minuciosa de problemas particulares, de modo que, ainda que em princípio não exclua a sua integração em sistemas mais abrangentes, de modo algum a requer: antes os debates o ignoram, para fixar o foco sobre este ou aquele assunto. Isso, ressalta Scott Soames (2003), é principalmente uma característica da filosofia analítica tal como praticada nas últimas décadas, em decorrência da rigorosa especialização que marca o perfil profissional dos participantes. No princípio, porém, um aporte mais universal geralmente se obtinha pela imposição de limites ao "filosoficamente inteligível": em regra, questões sobre linguagem e acerca de teorias científicas tendiam a dominar o campo em detrimento de discussões sobre filosofia social e política, metafísica etc. Como vimos, porém, em sua fase atual, uma ampla variedade de áreas temáticas veio a ser incorporada, quase sempre ao custo da perda da unidade de perspectiva e da cada vez maior especialização dos debates. Tudo isso, claro, contribui para o agravamento da crise identitária. Diante de todo esse quadro, não surpreende a saída ensaiada por um autor como Hans-Johann Glock (2008), de considerar o princípio de unidade da filosofia analítica como algo fundamentalmente vago, a ser captado pelo conceito wittgensteiniano de "semelhanças de família".

\section{Um paradigma de racionalidade?}


Como vimos, apesar da ausência de consensos metodológicos e de teses em comum, é frequente a associação, entre os seus praticantes, da filosofia analítica com a boa filosofia pura e simples. Isso parece proceder não somente da ênfase na clareza e no rigor argumentativo, mas também da íntima conexão do movimento analítico com o desenvolvimento da moderna lógica matemática e de suas alegadas continuidades, por um lado com a pesquisa científica, e por outro com o "senso comum".

A constituição da lógica matemática a partir do século XIX se encontra com a dos precursores imediatos da filosofia analítica - os pioneiros do que Alberto Coffa (1991) denominou a "tradição semântica", iniciada por Bolzano - no esforço de tratar de dificuldades relacionadas ao conhecimento matemático (não só de um ponto de vista epistemológico "fundacional", recorda Coffa, mas em considerável medida com o fim de atingir maior clareza conceitual) após Kant ${ }^{2}$. A teoria kantiana do juízo, com sua característica tentativa de justificar a existência de juízos sintéticos a priori aparece, para os representantes dessa tradição, como resultante de confusões conceituais resultantes da incapacidade de distinguir (em casos concretos) entre ato e conteúdo e da indevida intromissão da intuição em matérias mais propriamente compreendidas como semânticas.

Coffa sugere que Kant provavelmente tinha em mente a tradição matemática britânica, em que os novos conceitos do Cálculo eram modelados segundo a analogia do movimento, trazendo as "intuições" do tempo e do espaço ao coração da própria prática matemática ${ }^{3}$. A ampla aplicabilidade daqueles recursos, porém, mais contribuiu

\footnotetext{
${ }^{2}$ Com efeito, Simon Critchley (op. cit.) argumenta que o cisma entre analíticos e continentais remonta à decisão entre seguir (criticamente) Kant como epistemólogo (partindo da Crítica da Razão Pura) e seguilo pelas direções apontadas em sua ética e estética (partindo da Crítica da Razão Prática e da Crítica da Faculdade de Julgar): tal separação seria responsável ainda pelo juízo comum de que os analíticos estão mais preocupados com a tecnicidade "científica" enquanto os continentais com os aspectos mais "sapienciais" (conquanto potencialmente "obscuros") da Filosofia.

${ }^{3}$ Paolo Mancosu (1996) faz a origem de tal apelo ao movimento remontar à matemática grega, tal como se manifesta em certas passagens de Euclides e Arquimedes, embora sua importância seja, em certo sentido, marginal. No século XVII viria a dominar o pensamento matemático na Europa, e não somente na Inglaterra.
} 
para a sua proliferação do que para a inteligibilidade dos conceitos em si mesmos. $O$ esforço de rigorização empreendido, por exemplo, por Lagrange e Cauchy, levaria a uma ênfase decidida sobre os processos de demonstração e a uma rejeição sistemática do papel da intuição na matemática, que teria expressão privilegiada no fenômeno da aritmetização da análise. A influência da álgebra arábica a partir do final da Idade Média conduziria ainda a uma guinada "formalista", com a introdução de técnicas de resolução destinadas principalmente a tornar mais eficientes os procedimentos de cálculo, ainda que utilizando construtos teóricos tidos como desprovidos de sentido, como as raízes quadradas de números negativos (v. SILVA, 2007). O formalismo algébrico chegou, afinal, à própria lógica, com a proposição, pelos algebristas britânicos, do que entendiam como uma formulação das "leis do pensamento" mais compreensiva que aquela da "lógica tradicional" (praticamente restrita, em sua versão manualista então predominante, à teoria do silogismo dos Primeiros Analíticos e a alguns aspectos da lógica proposicional estoica - sem consideração de certos desenvolvimentos medievais como a teoria das suppositiones [v. BROADIE, 1993]). Embora entendida em chave "kantiana" ou psicologista, a algebrização da lógica deu à disciplina a flexibilidade característica dos métodos da matemática moderna. As duas tendências convergiram nos desenvolvimentos posteriores de Peirce, Schröder, Frege, Peano, Russell e Whitehead (v. GRATTAN-GUINNESS, 2004; KNEALE \& KNEALE, 1971).

A matematização da lógica se apresenta nesse contexto, paradoxalmente, como instrumento da tese logicista, que pretende reduzir a matemática à lógica. Nem sempre se trata somente da construção de uma "lógica simbólica", cujas operações são definidas de modo análogo às das teorias matemáticas, mas frequentemente do emprego de recursos matemáticos na própria lógica. Um farto uso das quantidades é indispensável ao projeto dos Principia Mathematica de Russell e Whitehead ${ }^{4}$. Também o uso de conceitos da teoria de conjuntos é ubíquo. Seja como for, a lógica matemática, especialmente com as contribuições de Frege para a teoria da

\footnotetext{
${ }^{4} \mathrm{O}$ emprego de axiomas como o do infinito e o da redutibilidade, de estatuto lógico duvidoso, também são vistos como comprometedores para o projeto dos Principia.
} 
quantificação, assume, contrariamente à postura mais flexível e contextual dos algebristas (lógica como cálculo, posição a que se associa, no século XX, Löwenheim), uma feição universalista (lógica como meio universal) [v. HEIJENOORT, 1967). A lógica de Frege e Russell/Whitehead foi designada para comportar a tese de que as verdades da matemática (da aritmética, no caso de Frege) são analíticas, contrariando a alegação kantiana de que seriam sintéticas a priori. Portanto, identifica-se a uma concepção sobre a natureza da Lógica - que constituiria a ortodoxia moderna da lógica clássica.

Os recursos da nova lógica, para além das controvérsias fundacionais na matemática, foram logo utilizadas para disciplinar a discussão filosófica em sentido lato, gerando, por exemplo em Russell, a convicção de que os problemas da filosofia não mais seriam que problemas lógicos. Também Wittgenstein se amparou naqueles recursos para propor a visão metafísica das relações entre linguagem e mundo do Tractatus Logico-Philosophicus, que depois contaria com a adesão de Russell (o qual, por sua vez, Ihe emprestaria feições mais explicitamente empiristas), consolidando-se como uma filosofia do atomismo lógico. A seguir Russell se retiraria da linha de frente da filosofia analítica e Wittgenstein rejeitaria as teses do Tractatus. No entanto, o modelo proposto por este último influenciaria substancialmente o empirismo lógico dos membros do Círculo de Viena (tendência que teria em Ayer seu principal representante na Grã-Bretanha), empenhados em justificar uma visão científica do mundo pela regulamentação da linguagem, que deveria incluir a lógica de primeira ordem e enunciados redutíveis a protocolos de experiência. Tal esforço tinha entre suas motivações uma animosidade antimetafísica que atingiria inclusive a reformulação "copernicana" daquela disciplina, rejeitando a existência de verdades sintéticas a priori, o que os conduziu a aproximar-se do logicismo (v. GLOCK, 2008; HACKER, 2007).

A partir da década de 1930, essa relação entre a lógica e a matemática sofrerá uma mutação substantiva. Os resultados de incompletude de Gödel deram um sério 
golpe no projeto logicista (e também frustraram as expectativas de David Hilbert, que admitia na matemática uma parte "sintética", mas sem qualquer necessidade de apoio na "intuição", dada pelos axiomas de uma teoria, sendo que o restante se seguiria por via de dedução). A lógica deu uma nova guinada algébrica com Tarski e seu projeto de uma semântica científica baseada em estruturas abstratas "semi-formalizadas" que introduziram uma dimensão "interpretativa" às teorias lógicas (desenvolvendo certas linhas abertas, por exemplo, por Löwenheim e Skolem ${ }^{5}$ ) e prepararam o terreno para a teoria de modelos, hoje uma das áreas centrais dos estudos lógicos (v. GRATTANGUINNESS, op. cit.).

Enquanto os estudos pioneiros de Post e Lukasiewicz sobre formalismos alternativos aos de Frege e de Russell e Whitehead levaram-nos a propor alternativas à "lógica clássica" (lógicas polivalentes) e a contestação de C. I. Lewis da implicação material dos Principia o motivariam a propor uma ideia de necessidade de implicação que influenciaria o surgimento da lógica modal (moderna, já que a modalidade em lógica fora estudada em detalhe por Aristóteles e pelos escolásticos) e a proposta contrária tanto ao formalismo quanto ao logicismo, o intuicionismo defendido por Brouwer, havia inspirado a elaboração de uma lógica que não assume a validade de um princípio como o terceiro excluído, os resultados de Gödel (entre os quais podemos ainda incluir sua prova da completude da lógica de primeira ordem) e Tarski ensejaram uma distinção cada vez mais nítida entre teoria e metateoria em lógica (v. KNEALE \& KNEALE, op. cit.; GRATTAN-GUINNESS, op. cit.; SILVA, op. cit.). Com os paradoxos que se acumularam em torno da teoria de conjuntos (como vimos, amplamente empregada pelos lógicos) desde Cantor, além daqueles que cercavam as discussões das novas teorias semânticas, que justificavam a proliferação de teorias

\footnotetext{
${ }^{5}$ A tendência de encontrar procedimentos não axiomáticos de decisão sobre a validade de fórmulas já havia levado ao desenvolvimento das técnicas de tabelas de verdade, inspiradas na álgebra booleana, com Wittgenstein, Post e Lukasiewicz - sendo que estes dois últimos estenderam seus estudos ao que seriam lógicas não bivalentes. Também C. I. Lewis cultivou interesse por questões de semântica, o que o levou a introduzir sua discussão sobre a implicação estrita, germe das modernas lógicas modais ( $v$. KNEALE \& KNEALE, op. cit.; GRATTAN-GUINNESS, op. cit.).
} 
distintas e não equivalentes, um senso de pluralismo se formava entre os lógicos profissionais (v. COSTA, 1980). A partir do final da década de 1920 e dos primeiros anos da de 1930, com os trabalhos de Glivenko, Gödel, Gentzen e Kolmogorov, já se realizavam as traduções entre diversos sistemas lógicos (com alguns resultados surpreendentes, como a inter-traduzibilidade entre as lógicas clássica e intuicionista, com preservação de teoremas em ambas as direções) [v. BATISTA NETO, 2007].

Essa situação somente se aprofunda com o passar do tempo. John Woods (2003) afirma que, ainda nas primeiras décadas do século XX, as ciências formais - e entre elas a Lógica - atingem um estágio pós-moderno em sua história. As abordagens da "linguagem ideal" em Filosofia perdem cedo seu monopólio (v. RORTY, op. cit.; GLOCK, op. cit.; HACKER, 2007). Onde sobrevivem, mesmo entre os empiristas lógicos, como Carnap, assumem uma direção mais pragmatista. Carnap afirma a relatividade da Lógica, assumindo em relação a ela uma postura instrumentalista. Um autor importante, ainda que marginalizado, associado àquele movimento, Louis Rougier, defende em detalhe essa posição, alegando que, com essa descoberta, a humanidade teria enfim incinerado seu derradeiro ídolo (v. BÉZIAU, 2014). Seja como for, o fato é que o desenvolvimento de lógicas "heterodoxas" se tornou uma prática corrente entre os lógicos. A concepção de uma lógica como uma estrutura matemática de determinada espécie deu origem ao problema geral da representação de sistemas lógicos e de como definir operações entre eles: traduções, morfismos, combinações (v. BATISTA NETO, op. cit.).

Embora a discussão inicial tenha girado em torno da questão de substituir globalmente a lógica clássica - que, em virtude da notável elegância, simplicidade, vasta aplicabilidade e disponibilidade de diversas propriedades metateóricas atraentes, permanece como basilar -, logo a posição pluralista (que defende a existência de mais de uma lógica "correta") ganhou destaque. Algumas perspectivas, como aquela de Richard Epstein (2012), dão ainda certa centralidade à lógica clássica, tomada como um ponto de origem. No entanto, mesmo entre os defensores da 
soberania da lógica clássica, a atitude de fundadores como Frege e Russell já não mais parece defensável. Quine (1963), talvez o mais célebre deles, não hesitava em afirmar que a Lógica é essencialmente revisável, e sua opção pela lógica clássica é justificada em termos eminentemente pragmáticos. Tarski (2007), um dos grandes responsáveis pela consolidação da ortodoxia em sua forma atual, admite que sua apresentação do conceito de consequência lógica (considerado pela maioria dos autores atuais como o conceito lógico fundamental), por se amparar no uso vago e nem sempre consistente da "linguagem comum", carrega um grau de inescapável arbitrariedade. Essa flutuação possível no sentido do conceito de consequência lógica é o ponto de partida do argumento de Beall e Restall (2006), um dos mais famosos e influentes, em favor do pluralismo lógico.

Esses debates, porém, fizeram-se largamente à margem das discussões centrais dos filósofos analíticos - restringindo-se ao âmbito, já bem demarcado, da filosofia da lógica. No entanto, em meados do século $X X$, a preocupação com a linguagem combinou-se com um retorno aos critérios de análise fundados no "senso comum" à Moore para constituir a chamada filosofia da linguagem ordinária, que encontra expressão no Wittgenstein das Investigações Filosóficas e nos filósofos firmados em Oxford. Céticos a respeito da capacidade das linguagens artificiais baseadas na nova lógica para oferecer critérios legítimos de análise linguística de modo a atacar os problemas tradicionais da filosofia (seja dissolvendo-os ou resolvendo-os), propõem antes ater-se aos sentidos vinculados aos usos correntes nas linguagens naturais. Um uso purificado de contaminações metafísicas seria capaz de determinar o significado próprio dos termos (ou pelo menos no interior de determinado "jogo de linguagem"), de modo a por fim às controvérsias que dividem os filósofos (assumidas como referentes, senão exclusivamente ao menos em grande medida, ao significado dos termos e ao que disso decorre). Com Grice e Searle, a vinculação do uso à intenção abre espaço para o retorno das representações mentais e, com ela, de toda a problemática sobre a mente inaugurada por Descartes - 
discussão que pegou carona com o desenvolvimento das neurociências e da pesquisa em Inteligência Artificial (em que questões mais formais que requerem o uso da lógica tornam a aparecer - como nas controvérsias entre conexionistas e defensores da "linguagem do pensamento") [v. GLOCK, 2008; FESER, 2006]. Paralelamente, o uso das linguagens formais é sistematicamente empregado, sobretudo nos Estados Unidos, associado a algumas tendências predominantes no pensamento nativo daquele país sobretudo o pragmatismo e o behaviorismo - para constituir um pragmatismo lógico (Quine, Davidson) que rompe com os princípios da análise e assume uma postura naturalista (continuidade entre filosofia e ciência) e holista (em busca de uma filosofia que articule o corpo da Ciência) [v. GLOCK, 2003]. Numa direção radicalmente diferente, os desenvolvimentos da lógica modal inspiraram um retorno da especulação metafísica, sobretudo após a criação da semântica kripkeana de mundos possíveis. Por outro lado, com Lakatos, Kuhn e Feyerabend, a historicidade faz uma significativa entrada na filosofia da ciência (embora tenda a permanecer por lá). Essa divisão de áreas já é suficiente para uma separação das discussões, que irá somente se intensificar com o tempo. Pouco a pouco, o campo de interesse dos filósofos analíticos se alarga, mas as subdisciplinas filosóficas vão se tornando autônomas - de modo que acabam por muitas vezes por supor como certo o que, no seu próprio campo de debate, é objeto de acirrada disputa.

Os sistemas de lógica alternativos ao clássico passaram a receber justificativa filosófica (v. p. ex., PRIEST, 2006; DUMMETT, 1978a), mas o próprio fato de que princípios elementares da Lógica viessem a ser postos em questão pela discussão dos filósofos revela a profundidade da ausência de acordos entre eles. Com efeito, como observa Maclntyre (1990a), um dos dados mais notáveis sobre as posições dominantes em Filosofia atualmente, quer entre continentais quer entre analíticos, é a comum rejeição de primeiros princípios (o que é, claro, uma espécie de acordo, embora uma que deixe pouca esperança sobre o estabelecimento de outros). Do ponto de vista dos sistemas formais, nada além de uma escolha particular de heurística justifica a 
admissão de uma determinada fórmula (a que se pode reduzir o princípio da nãocontradição ou do terceiro excluído) à lista dos seus axiomas (e há apresentações equivalentes que os dispensa de todo), já que podem integrar os teoremas derivados de um conjunto alternativo deles - interessando somente que se incluam entre as teses do dito sistema. A tentativa de justificá-los tende a ser extra-sistemática, e quase sempre, de fato, é extra-filosófica.

Soames (op. cit.) chega a afirmar que as duas contribuições principais da filosofia analítica (que ele considera como resultados estabelecidos) são o reconhecimento de que a especulação filosófica deve ser amparada no pensamento pré-filosófico e o ganho na compreensão e distinção de conceitos metodológicos ligados à Lógica. Sobre este último ponto, vimos que a Lógica moderna encontra grandes dificuldades em se estabelecer como modelo de racionalidade, de modo que a luz que se lança sobre os conceitos nela operantes podem não contribuir para o sucesso da razão filosófica em sentido lato. Sobre o primeiro, é importante fazer algumas observações. As duas fontes usuais de "pensamento pré-filosófico" a que se recorre são o "senso comum" (ou "uso ordinário" da linguagem) e as ciências (ou "as melhores teorias científicas").

Ora, já reparamos que, no primeiro caso, o uso ordinário é de tal modo vago e incoerente que um conceito como o de consequência lógica pode receber, a partir dele, diversas formulações não equivalentes. Falar da autonomia dos "jogos de linguagem" para eludir a questão é evadir-se à consideração de se há um entre eles que seja o mais apropriado para o debate das questões filosóficas tradicionais, e não demonstrar que este não existe. Mais ainda: a ideia de uma "linguagem ordinária" livre de "contaminações metafísicas" é uma ficção sociológica: como aponta David Oderberg (2007), a linguagem natural é saturada de metafísica; os sentidos ordinários dos termos, além do mais, estão em constante mutação. Se propor a substituição das diversas tradições filosóficas por uma filosofia preocupada com o "uso comum" supõe antes que demonstra a inadequação daquelas (sem conseguir eliminar sua influência), 
partir de tais usos supostamente (mas inconsistentemente) "pré-filosóficos" é um ponto de partida no mínimo discutível para o resgate da metafísica que hoje se procura fazer.

Similarmente no caso das ciências: o sentido dos termos tende a variar com a sucessão das teorias admitidas, as quais se amparam sobre marcos metodológicos notoriamente heterogêneos e frequentemente se pautam por critérios de eficiência de predição e controle que só por uma arbitrária intervenção, ela própria de natureza filosófica, se pode interpretar como tendo importância ontológica. Além do mais, é um fato histórico que a linguagem e o estilo das ciências se deixam igualmente influenciar por aqueles dos filósofos. Especialmente após a virada histórica na filosofia da ciência, a subordinação dos princípios da filosofia àqueles das ciências aparece como uma opção arbitrária e especialmente instável: e não se demonstra que é preciso que assim seja, mas antes é suposto ${ }^{6}$.

$\mathrm{Na}$ ausência de primeiros princípios admitidos e outros acordos metodológicos, a conclusão de David Lewis (1983, p. xi) parece inevitável: "uma vez que o cardápio de teorias bem elaboradas está diante de nós, a filosofia é uma questão de opinião". Essas opiniões, conforme observamos, por serem formuladas em contextos altamente específicos, não só carecem em geral de integração num quadro maior (que articule, por exemplo, epistemologia, metafísica, ética e teoria social de forma coerente), como, ao se remeterem a elementos emprestados de outras áreas da filosofia ou demais setores do conhecimento (lógica, linguística etc.) como premissas ou recursos formais, geralmente ignoram a complexidade e o caráter controverso dos debates que lhes são característicos.

\section{A crítica no contexto do projeto MacIntyreano}

\footnotetext{
${ }^{6}$ É claro que aqui se poderia recorrer a argumentos céticos sobre o poder e o alcance da "filosofia tradicional" e então redefinir as tarefas da Filosofia. Mas o termo "filosofia tradicional" é equívoco, e as críticas que se dirigem a esse rótulo podem não atingir todas as tradições. Com efeito, isso faz parte da argumentação de MacIntyre. Além do mais, também a proposta de redefinição da Filosofia pode ser confrontada no nível metafilosófico.
} 
Maclntyre faz diversas críticas incidentais às posições características da filosofia analítica (que podemos tentar articular). Afirma (2007) que, embora os filósofos analíticos tendam, em regra, a rejeitar a posição emotivistas em filosofia moral $^{7}$ (i.e., a tese de que as prescrições da moralidade se reduzem à expressão de determinadas emoções) por falhar em perceber as distinções de significado entre enunciados morais e enunciados sobre sentimentos e emoções, a ausência de acordos fundamentais entre eles termina por legitimar uma forma de emotivismo não como teoria do significado, mas como uma do uso moral, para quem procura abarcar, de uma perspectiva ampla, as divergências que separam os filósofos uns dos outros ${ }^{8}$. Nesse sentido, a filosofia analítica reencena a "catástrofe" trazida pela filosofia moderna: embora desconfiando da proposição de "primeiros princípios" (tomados, quer pelos modernos que os aceitaram, quer pelos analíticos - e continentais - que os rejeitam, em sentido eminentemente epistemológico ${ }^{9}$ ), veem-se geralmente obrigados a admitir que a justificação racional de um juízo moral se funda numa cadeia finita de proposições concatenadas em argumento, que remetem a proposições iniciais para as quais não se pode dar razões ulteriores. Na falta de acordos sobre princípios comuns, as perspectivas de resolução dos conflitos que dividem entre si os filósofos analíticos são nulas - o que termina por fazer da opção entre diversos pontos de partida, em última análise, uma questão de "gosto". À irresolução dos debates se une a incapacidade de as instituições e práticas das sociedades hodiernas justificarem-se racionalmente pela aplicação dos princípios de qualquer uma das perspectivas que dominam os debates entre os filósofos morais (seja kantiana, utilitarista ou uma forma da ética das virtudes) para garantir a irrelevância da maior parte dos debates filosóficos para a ordem social concreta (2006b). Essa situação é agravada pela profissionalização e superespecialização da atividade filosófica, que asseguram um

\footnotetext{
7 O próprio Maclntyre menciona exceções como Carnap, C. L. Stevenson e Simon Blackburn (2007; 2006a).

${ }^{8} \mathrm{~V}$. a citação de Lewis acima, reproduzida pelo próprio Maclntyre em mais de um lugar.

9 O que marca um contraste com os antigos e medievais, em geral não reconhecido pelos contemporâneos. V. MACINTYRE, 1990a.
} 
ambiente apropriado para a discussão filosófica que previne o seu impacto sobre a ordem social mais ampla (2010).

A ausência de princípios comuns relaciona-se à de um ordenamento teleológico que nos capacite a medir os progressos atingidos no interior da tradição (1990a). É característico dos filósofos analíticos (v. RORTY, op. cit.; SOAMES, op. cit.) afirmarem que, não obstante a carência dessa direção, é possível apontar progressos na refutação de formulações específicas de determinadas teses ou problemas, assim como no aperfeiçoamento da prática de enunciar e rebater objeções, além da elaboração de um aparato técnico-conceitual mais finamente calibrado para emprego nas discussões. Maclntyre reconhece cada um desses pontos (1990a), mas observa que nenhum desses progressos conduz ao vislumbre de algum meio de eliminar os desacordos fundamentais entre os filósofos, de maneira a serem atingidos resultados mais substanciais - e algo como um perspectivismo nietzscheano seria ainda aplicável como diagnóstico da situação reinante. Com efeito, Maclntyre observa uma convergência entre a filosofia burocratizada e fragmentada praticada pelos analíticos (a referência feita aqui é à filosofia profissional contemporânea nos Estados Unidos da América) e aquela dos escolásticos tardios: uma filosofia caracterizada pelo desacordo em princípios fundamentais, em que a participação é condicionada por exigências curriculares burocraticamente sancionadas referente ao domínio de técnicas lógicoconceituais, cujo grau de sucesso é medida pela excelência na habilidade profissional demonstrada na formulação e uso dessas mesmas técnicas ${ }^{10}$ (1990a).

Essas características da filosofia analítica fazem dela uma filosofia sob medida para a sociedade liberal, alvo preferido das críticas macintyreanas. A fragmentação da filosofia reflete a fragmentação do ego liberal, dividido entre interesses divergentes e

\footnotetext{
${ }^{10}$ Ao contrário da filosofia analítica, porém, o escolasticismo do século XIV não resulta de uma revolução filosófica, mas antes de uma reação de uma filosofia enquadrada numa estrutura curricular e institucional ao aparecimento de um sistema filosófico amplo (no caso, o aristotélico) que ele não saberá incorporar (muito embora a própria reação tenha aberto caminho para inovações técnicoconceituais que ajudarão a preparar a moderna revolução científica). Além do mais, há ainda nesta última sensível acordo sobre princípios, seu significado mais amplo e suas raízes numa compreensão relativamente articulada do homem e do mundo.
} 
com frequência inconciliáveis (1988). A ausência de uma direção teleológica, a noção de uma prática filosófica divorciada dos fins próprios da existência humana (como ressalta Soames, a filosofia conduzida na tradição analítica ocupa-se da busca da "verdade", sem interessar-se pelo aperfeiçoamento moral ou espiritual - no que admite que ambas as dimensões se encontram separadas ${ }^{11}$ ) espelha a compartimentalização das esferas de atividade, que impede a identificação (que dirá o florescimento) de uma virtude humana enquanto tal (2006b). Isso leva a uma prática filosófica profissionalizada, regida por conformações burocráticas que, ao mesmo tempo em que consagram a ideia de um pluralismo invocado para legitimar a ordem liberal como instância supostamente neutra, garante que a discussão filosófica permanecerá ineficaz como forma de contestação dessa mesma ordem (ibid.). A tradição analítica apresenta o mesmo viés a-histórico e a mesma resistência em reconhecer-se como uma tradição fundada sobre compromissos de alguma espécie, que a tradição liberal. Ainda quando se interessam pela história da Filosofia, os filósofos analíticos em regra estão interessados em construir uma história particularmente analítica da disciplina (v. SORELL \& ROGERS, 2005; SCRUTON, 2007): reconstruindo os argumentos de filósofos do passado de modo a torná-los inteligíveis e relevantes para as discussões atuais, mais do que preocupando-se com detalhes de erudição histórica e cultural que permitam situá-los no contexto geral que lhes deu origem. Maclntyre afirma que tal é justamente o que se dá com o recente interesse lançado sobre a Idade Média, tal como se manifesta numa obra como The Cambridge History of Latter Medieval Philosophy (KRETZMANN et al., 1982), onde os autores são saudados sobretudo como antecipadores de aspectos do trabalho dos filósofos analíticos hodiernos. Isso tem por efeito obstar que haja um autêntico confronto de tradições, que permitisse questionar os pressupostos da própria tradição analítica a partir de uma perspectiva aberta por uma outra tradição.

${ }^{11}$ Como nota Maclntyre, precisamente o oposto do que ocorre na tradição clássica. A falta de uma percepção da verdade como bem, que condiciona a visão do inquérito filosófico como uma atividade dirigida pela virtude e voltada ao aperfeiçoamento do homem enquanto pesquisador, é um defeito fundamental apontado por MacIntyre nas teorias analíticas sobre a verdade. 
Tais apontamentos poderiam lançar luz sobre o próprio problema da identidade da tradição analítica. Embora tenha raízes em certos debates da filosofia continental europeia do século XIX, que emergem de dificuldades percebidas no pensamento de Kant e relacionadas sobretudo ao estatuto do conhecimento matemático ${ }^{12}$, a filosofia analítica se firma como movimento na Grã-Bretanha, nas primeiras décadas do século XX. Thomas Akehurst (op. cit.), haurindo de um estudo da atmosfera cultural britânica na primeira metade do século XX e de diversas declarações de figuras proeminentes no movimento analítico (Russell, Ayer, Ryle, Hare, Berlin, entre outros), afirma que a filosofia analítica firmou-se, em grande medida, como herdeiro de um espírito liberal tipicamente britânico ${ }^{13}$, em contraste com um "anti-cânon" continental (capitaneado por um Hegel bastante ideologicamente deformado ${ }^{14}$ ) responsabilizado pelas ameaças alemãs nas duas grandes guerras. Akehurst insiste nos aspectos nacionalistas desse vínculo ${ }^{15}$ (dos quais indica, aliás, a incoerência), mas o fato é que, assim como a tradição liberal, a filosofia analítica é um produto para exportação. Hans Sluga (1997) chega a afirmar que a filosofia analítica é a única filosofia realmente supranacional desde o fim da escolástica medieval associando seu sucesso internacional a seu caráter a-histórico. Também Follesdal (op.

\footnotetext{
${ }^{12}$ Obviamente, esses aspectos da sua gênese também têm os seus condicionantes culturais, alguns dos quais permanecem, sem solução de continuidade, na tradição analítica. A centralidade, para o projeto moderno, da ciência física pós-galileana - cujos sucessos serão medidos principalmente em termos de resultados de predição e controle, conformes ao espírito "prometeico" da cultura moderna -, gera os problemas (associados ao que Whitehead [2006] chama a "metafísica da posição simples") que convocarão a solução kantiana de vincular a ordem percebida no universo, não mais ao universo em si mesmo, mas às condições de sua apreensão pelo sujeito conhecedor. Gavin Ardley (op. cit.) vê nas posições características da virada linguística um "neokantismo" que projeta a insustentável arquitetônica do sujeito kantiano sobre as convenções públicas da linguagem (consagrando o que Rorty chamaria "nominalismo metodológico"), e enfatiza a descontinuidade de ambas em relação à metafísica e à filosofia da natureza clássicas (para uma visão similar, v. MARITAIN, 1947, 2003). Para um contraste fundamentado entre a atitude epistemológica dos modernos e a atitude metafísica do tomismo (e defesa desta última), v. GILSON, 1974, 1983 (esta última obra aludida pelo próprio Maclntyre [1990a]).

${ }^{13}$ Que remonta, principalmente, a Locke. Para uma apreciação da medida em que o status quo políticocultural moderno (especialmente no mundo anglo-saxão) depende de Locke, e de como as teses lockeanas assentam sobre uma pouco consistente rejeição das posições tradicionais escolásticas, $v$. FESER, 2007.

${ }^{14} \mathrm{~V}$. também o artigo de Kauffmann, na coletânea organizada por Maclntyre (1976).

${ }^{15}$ Remete também ao trabalho de John McCumber para o contexto político-cultural do estabelecimento da filosofia analítica nos Estados Unidos da América.
} 
cit.) crê que a filosofia analítica deveria ser praticada não apenas por identificá-la à "boa filosofia", mas ainda por sua alegada importância para a democracia (entendida claramente aqui em sentido liberal).

\section{Considerações Finais}

A identificação pura e simples da filosofia analítica com a "boa filosofia" e a reivindicação, por essa tradição, de um tipo superior de racionalidade filosófica são teses que encontram um número cada vez maior de objetores, incluindo autores formados em seus cânones. O projeto filosófico de Alasdair Maclntyre, que é um autor intimamente relacionado com aquela tradição, acrescenta em profundidade às críticas comuns, especialmente dada a sua fecunda perspectiva metafilosófica sobre tradições em conflito e sua firme adesão à tradição aristotélico-tomista.

Uma narrativa da história da tradição analítica e uma análise das afirmações comuns entre seus representantes no sentido de apresentá-la como uma forma superior de racionalidade podem mostrar a falha dessa tradição em sustentar-se segundo seus próprios critérios, mostrando que, de uma perspectiva metafilosófica, a tradição tende a colapsar em um tipo de perspectivismo pós-moderno aparentado àquele esposado por Nietzsche e seus herdeiros diretos, que constitui, em certo sentido, a antítese do ideal sobre o qual a filosofia analítica foi fundada e que constituiu, historicamente, a fonte de seu prestígio.

Há aspectos dessa crítica que convergem com o trabalho de representantes da filosofia tomista ou neoescolástica contemporânea em diálogo com a tradição analítica. Os pressupostos da chamada "virada linguística" (que de certo modo dominou o panorama daquela tradição e continua a exercer sobre ela substancial influência), as teorias da quantificação e da referência, as posições características da filosofia da mente, as concepções sobre causalidade, a ressurreição da metafísica em versão modalista, todos esses são alvos do juízo crítico de autores como John P. O’Callaghan, Gyula Klima (2001, 2002, 2004), Edward Feser (2006, 2014), John Haldane 
Batista Neto, A. L.

Para uma crítica macintyreana da filosofia analítica

(2002a) e David Oderberg (2007), que destacam não somente a superioridade das soluções aristotélico-tomistas como a dependência do que veem como as dificuldades instransponíveis enfrentadas pelas linhas dominantes da filosofia analítica sobre premissas metodológicas equivocadas e compromissos filosóficos problemáticos (e nem sempre reconhecidos). Pensamos que a perspectiva metafilosófica fundada sobre o programa macintyreano acerca das tradições de pesquisa, juntamente com apontamentos realizados pelo próprio Maclntyre, ajudam a dar a essas críticas uma mais completa articulação. 


\section{Referências}

AKEHURST, Thomas. The Cultural Politics of Analytic Philosophy: Britishness and the Spectre of Europe. London, New York: Continuum, 2010.

ARDLEY, Gavin. Aquinas and Kant: The Foundations of Modern Science. London, New York, Toronto: Longmans, Green \& Co., 1950.

BATISTA NETO, Alberto Leopoldo. Representação e combinação de lógicas: Questões conceituais. Dissertação de Mestrado: Instituto de Filosofia e Ciências Humanas, Universidade Estadual de Campinas. Campinas, 2007.

BEALL, J. C.; RESTALL, Greg. Logical pluralism. Oxford: Clarendon, 2006.

BÉZIAU, Jean-Yves. The relativity and universality of logic. Synthese. DOI 10.1007/s11229-014-0419-0, 20 March 2014.

BROADIE, Alexander. Introduction to Medieval Logic. 2. ed. Oxford: Clarendon, 1993. COFFA, J. Alberto. The Semantic Tradition from Kant to Carnap: to the Vienna station. Melbourne: Cambridge, 1991.

COSTA, Newton C. A. da. Ensaio sobre os Fundamentos da Lógica. 2. ed. São Paulo: HUCITEC, EDUSP, 1980.

CRITCHLEY, Simon. Continental Philosophy: A Very Short Introduction. New York: Oxford University, 2001.

DUMMETT, Michael. The Logical Basis of Metaphysics. Cambridge: Harvard University, 1991.

Origins of Analytical Philosophy. London: Duckworth; Cambridge: Harvard University, 1993. . Truth. In: . Truth and Other Enigmas. Harvard University, 1978, pp 1-24.

EPSTEIN, Richard. Propositional logics: The Semantic Foundations of Logic. 3. ed. Socorro (NM): ARF, 2012.

FESER, Edward. Philosophy of mind: A Beginner's Guide. Oxford: Oneworld, 2006. Locke. Oxford: Oneworld, 2007. 
Scholastic Metaphysics: A Contemporary Introduction. Heusenstamm:

Editiones Scholasticae, 2014.

FOLLESDAL, Dagfinn. Analytic Philosophy: What Is It and Why Should One Engage in It? In: GLOCK, Hans-Johann. The Rise of Analytic Philosophy. Oxford: Blackwell, 1997. GILSON, Etienne. El realismo metódico. Trad. Valentín García Yebra. 4. ed. Madrid: Rialp, 1974.

Thomist Realism and the Critique of Knowledge. Trad. Mark A. Wauck. San

Francisco: Ignatius, 1983.

GLOCK, Hans-Johann. Quine and Davidson on Language, Thought and Reality. New York: Cambridge University, 2003.

What is Analytical Philosophy? New York: Cambridge University, 2008.

GRATTAN-GUINNESS, Ivor. The Mathematical Turns in Logic. In: GABBAY, Dov M.; WOODS, John (Eds.). The Rise of Modern Logic from Leibniz to Frege: Handbook of the History of Logic, Volume 3. Amsterdam: North-Holland, 2004.

HACKER, P. M. S. Analytic philosophy: what, whence, and whither? In: BILETZKI, Anat; MATAR, Anat (Eds.). The Story of Analytic Philosophy: Plot and Heroes. New York: Routledge, 1998.

- Analytic philosophy: beyond the linguistic turn and back again. In: BEANEY, Michael (Ed.) The Analytic Turn: Analysis in Early Analytic Philosophy and Phenomenology. New York: Routley, 2007, pp. 125-141.

HALDANE, John. (Ed.). Mind, Metaphysics, and Value in the Thomistic and Analytical Traditions. Indiana: University of Notre Dame, 2002.

. The Breakdown of Contemporary Philosophy of Mind. In: 2002, p. $54-75$. (2002a)

HEIJENOORT, Jean Van. Logic as Calculus and Logic as Language. Synthese (1967) 324330. D. Reidel. Dordrecht.

KAUFFMANN. The Hegel Myth and Its Method. In: MACINTYRE, 1976. 
KLIMA, Gyula. Contemporary “Essentialism” vs. Aristotelian Essentialism. In: HALDANE, 2002.

. Existence and reference in medieval logic. In: HIEKE, Alexander; MORSHER, Edgar. (Eds.) New Essays in Free logic. Dordrecht: Kluwer, 2001, p. 197-226.

On Kenny on Aquinas on Being. International Philosophical Quaterly. 44 (4):

567-580 (2004).

KNEALE, William; KNEALE, Martha. The Development of Logic. London: Oxford (Clarendon), 1971.

KRETZMANN, Norman; KENNY, Anthony; PINBORG, Jan; STUMP, Eleonore (Eds.). The Cambridge History of Later Medieval Philosophy. Melbourne: Cambridge, 1982.

LEWIS, David. Philosophical Papers: Volume I. New York, Oxford: Oxford University, 1983 (Introduction)

MACINTYRE, Alasdair (Ed.). Hegel: A Collection of Critical Essays. University of Notre Dame, 1976.b

Whose Justice? Which Rationality? Indiana: University of Notre Dame, 1988.

. Three Rival Versions of Moral Enquiry: Encyclopaedia, Genealogy, and Tradition. Indiana: University of Notre Dame, 1990a.

First Principles, Final Ends and Contemporary Philosophical Issues. Milwaukee: Marquette University, 1990b (Aquinas Lecture).

. The Tasks of Philosophy: Selected Essays, Volume I. New York: Cambridge University, 2006

Moral relativism, truth and justification. In: MACINTYRE, 2006, pp. 52-73. (2006a)

Moral philosophy and contemporary social practice: what holds them apart? In: MACINTYRE, 2006, pp. 104-122. (2006b)

. Philosophy recalled to its tasks: a Thomistic reading of Fides et Ratio. In: MACINTYRE, 2006, pp.179-196. (2006c) 
Truth as a good: a reflection on Fides et Ratio. In: MACINTYRE, 2006, pp. 197215.

After Virtue: A Study in Moral Theory. 3. ed. Indiana: University of Notre Dame, 2007.

On Not Knowing Where You Are Going. Proceedings and Addresses of the American Philosophical Association, Vol. 84, No. 2(November 2010), pp. 61-74. MANCOSU, Paolo. Philosophy of Mathematics and Mathematical Practice in the Seventeenth Century. New York, Oxford: Oxford University, 1996.

MARITAIN, Jacques. Distinguer pour Unir ou les Degrés Du Savoir. 4. ed. Paris: Desclée de Brouwer, 1947.

A Filosofia da Natureza. Tr. Luiz Paulo Rouanet. São Paulo: Loyola, 2003.

MICHELETTI, Mario. Tomismo analítico. Trad. Benôni Lemos, Patrizia Collina Bastianeto. Aparecida (SP): Ideias \& Letras, 2009.

O'CALLAGHAN, John P. Thomist Realism and the Linguistic Turn: toward a more perfect form of existence. Indiana: University of Notre Dame, 2003.

ODERBERG, David. Real Essentialism. New York, London: Routledge, 2007.

PRESTON, Aaron. Analytical Philosophy: The History of an Illusion. London, New York: Continuum, 2010.

PRIEST, Graham. In Contradiction: A Study of the Transconsistent. 2. ed. Oxford: Clarendon, 2006.

QUINE, W. V. Two dogmas of empiricism. In.: From a Logical Point of View. New York, Evanston: Harvard University, Harper \& Row, 1963.

RORTY, Richard M. (Ed.) The Linguistic Turn: essays on philosophical method. Chicago, London: University of Chicago, 1992.

SCRUTON, Roger. Breve História da Filosofia Moderna: De Descartes a Wittgenstein. Trad. Eduardo Francisco Alves. Rio de Janeiro: José Olympio, 2008.

SILVA, Jairo José da. Filosofias da Matemática. São Paulo: UNESP, 2007. 
SLUGA, Hans. What Has History to Do with Me? Wittgenstein and Analytic Philosophy. Inquiry, 41, 99-121 (1997).

SOAMES, Scott. Philosophical Analysis in the Twentieth Century: Volume I: The Dawn of Analysis. Princeton, Oxford: Princeton University, 2003.

SORELL, Tom; ROGERS, G. A. J. (Eds.). Analytic Philosophy and History of Philosophy.

Oxford: Clarendon, 2005.

TARSKI, Alfred. Sobre o Conceito de Consequência Lógica. Trad. Celso R. Braida. In: MORTARI, Cezar Augusto; DUTRA, Luiz Henrique de Araújo (Orgs.). A Concepção Semântica da Verdade: Textos Clássicos de Tarski. São Paulo: UNESP, 2007.

WHITEHEAD, Alfred North. A ciência e o mundo moderno. Trad. Hermann Herbert Watzlawick. São Paulo: Paulus, 2006.

WILLIAMSON, Timothy. Past the Linguistic Turn? In: LEITER, Brian. The Future for Philosophy. Oxford: Clarendon, 2004, pp. 106-128.

WOODS, John. Paradox and Paraconsistency: Conflict Resolution in the Abstract Sciences. Edinburgh, New York: Cambridge University, 2003. 